\title{
Massive and Specific Dysregulation of Direct Cortical Input to the Hippocampus in Temporal Lobe Epilepsy
}

\author{
Chyze W. Ang, ${ }^{1,2 \star}$ Gregory C. Carlson, ${ }^{2 \star}$ and Douglas A. Coulter ${ }^{1,2,3}$ \\ ${ }^{1}$ Department of Bioengineering, University of Pennsylvania, ${ }^{2}$ Division of Neurology, Children's Hospital of Philadelphia, and ${ }^{3}$ Departments of Pediatrics, \\ Neurology and Neuroscience, University of Pennsylvania School of Medicine, Philadelphia, Pennsylvania 19104
}

\begin{abstract}
Epilepsy affects 1-2\% of the population, with temporal lobe epilepsy (TLE) the most common variant in adults. Clinical and experimental studies have demonstrated hippocampal involvement in the seizures underlying TLE. However, identification of specific functional deficits in hippocampal circuits associated with possible roles in seizure generation remains controversial. Significant attention has focused on anatomic and cellular alterations in the dentate gyrus. The dentate gyrus is a primary gateway regulating cortical input to the hippocampus and, thus, a possible contributor to the aberrant cortical-hippocampal interactions underlying the seizures of TLE. Alternate cortical pathways innervating the hippocampus might also contribute to seizure initiation. Despite this potential importance in TLE, these pathways have received little study. Using simultaneous voltage-sensitive dye imaging and patch-clamp recordings in slices from animals with epilepsy, we assessed the relative degree of synaptic excitation activated by multiple cortical inputs to the hippocampus. Surprisingly, dentate gyrus-mediated regulation of the relay of cortical input to the hippocampus is unchanged in epileptic animals, and input via the Schaffer collaterals is actually decreased despite reduction in Schaffer-evoked inhibition. In contrast, a normally weak direct cortical input to area CA1 of hippocampus, the temporoammonic pathway, exhibits a TLE-associated transformation from a spatially restricted, highly regulated pathway to an excitatory projection with $>10$-fold increased effectiveness. This dysregulated temporoammonic pathway is critically positioned to mediate generation and/or propagation of seizure activity in the hippocampus.
\end{abstract}

Key words: dentate gyrus; entorhinal; hippocampus; inhibition; temporal lobe epilepsy; temporoammonic; voltage-sensitive dye imaging

\section{Introduction}

The hippocampus has been implicated in temporal lobe epilepsy (TLE) for three main reasons. First, seizure activity can be recorded from the hippocampus (Spencer and Spencer, 1994; Engel, 1995; Bertram 1997). Second, removal of the affected hippocampus eliminates seizures in $80-90 \%$ of TLE patients exhibiting unilateral mesial temporal lobe sclerosis (Falconer et al., 1964; Ojemann, 1987). Third, stereotypic neuropathology is found in the hippocampus of TLE patients that is recapitulated in animal models of TLE, termed hippocampal sclerosis (Schwartzkroin and Knowles, 1984; Sutula et al., 1988; Houser et al., 1990; French et al., 1993; Mello et al., 1993; Buckmaster and Dudek, 1997). Given that the hippocampus is critical in TLE, are there specific hippocampal circuits which could play a dominant role in the regulation of excitability, and could damaged function in these areas be particularly significant in the epileptic brain?

The primary cortical afferent to the hippocampus is the per-

Received June 2, 2006; revised Sept. 29, 2006; accepted Sept. 29, 2006.

This work was supported by National Institutes of Health Grants R37 NS-32403 and R01 NS-41811 (D.A.C.), a National Science fellowship from the Agency for Science Technology and Research, Singapore (C.W.A.), and an Epilepsy Research Award from the American Epilepsy Society (G.C.C.). We thank Shareen Nelson, Alicia White, and Dr. Mary Ellen Kelly for conduct of the histology; and Drs. Phil Haydon, Marc Dichter, Ana Lia Obaid, and Diego Contreras for critical review of this manuscript. We thank Dr. Leslie Loew for the generous gift of the dye JPW 3031. ${ }^{*}$ C.W.A. and G.C.C. contributed equally to this work.

Correspondence should be addressed to Dr. Douglas A. Coulter, Abramson Pediatrics Research Center, Room 410, 3516 Civic Center Boulevard, Philadelphia, PA 19104-4318. E-mail: coulterd@email.chop.edu. DOI:10.1523/JNEUROSCI.2354-06.2006

Copyright $\odot 2006$ Society for Neuroscience $\quad 0270-6474 / 06 / 2611850-07 \$ 15.00 / 0$ forant path, arising from layer II of entorhinal cortex, innervating the dentate gyrus. A secondary cortical afferent is the temporoammonic pathway, originating from layer III of entorhinal cortex, which projects directly to area CA1 (supplemental Fig. $1 A$, circuit diagram, available at www.jneurosci.org as supplemental material) (Steward and Scoville, 1976). In the normal hippocampus, synaptic inhibition within the dentate limits relay of cortical inputs downstream to area CA3, protecting against generation of hyperexcitability that leads to seizures (Heinemann et al., 1992; Lothman et al., 1992). Breakdown of the dentate "gate" has been hypothesized to be a primary contributor to seizure generation in epilepsy (Sutula et al., 1988; Heinemann et al., 1992; Lothman et al., 1992; Mello et al., 1993). Paradoxically, several TLE studies have indicated that inhibition within the dentate remains operative, and suppresses seizure propagation from the entorhinal cortex (Gibbs et al., 1997; Wilson et al., 1998; Wu and Leong 2001; Sloviter et al., 2006). Despite the controversy concerning the state of gate function of the dentate gyrus and disrupted intrinsic circuitry, the hippocampus remains critical in seizure generation. In view of these combined circuit considerations discussed above, could the temporoammonic pathway's direct channeling of cortical inputs to the hippocampus in the epileptic brain (Denslow et al., 2001; Wozny et al., 2005) assume an exaggerated importance?

To address these issues, we used voltage-sensitive dye (VSD) imaging and combined whole-cell dendritic patch recordings to determine changes in circuitry in the pilocarpine rat model of epilepsy. This animal model shares a natural history of develop- 
ment with human TLE in that it is characterized by a latent or silent period between the pilocarpine-induced initial injury and the onset of recurrent seizures, as well as shared neuropathology (French et al., 1993; Spencer and Spencer, 1994). High-speed voltage-sensitive dye imaging offers sufficient spatial and temporal resolution to record simultaneously membrane potential changes in 6400 voltage sensors at high sampling frequency (1-2 $\mathrm{kHz}$ ) (Davila et al., 1973; Salzberg et al., 1973; Contreras and Llinás, 2001; Ang et al., 2005), which enables coincident recording of afferent, intrinsic and efferent responses after synaptic activation in multiple hippocampal circuits.

\section{Materials and Methods}

Pilocarpine treatment. All experiments were performed in accordance with the National Institutes of Health Guidelines for the Care and Use of Laboratory Animals and with the approval of the Children's Hospital of Philadelphia Institutional Animal Care and Use Committee. Pilocarpine animals were produced using previously reported methods (Gibbs et al., 1997). Adult male Sprague Dawley rats (180-200 g) were pretreated with scopolamine methyl nitrate $(1 \mathrm{mg} / \mathrm{kg}$, s.c.) to antagonize peripheral effects induced by subsequent pilocarpine ( $405 \mathrm{mg} / \mathrm{kg}$, s.c.), injected 30 min later. This induced status epilepticus (STEP; i.e., sustained seizures lasting $>30 \mathrm{~min}$ ) within 10-30 min. One hour after STEP onset, diazepam $(7.5 \mathrm{mg} / \mathrm{kg}$, s.c.) was administered to quell seizure activity. Sham pilocarpine rats $(0.1$ control $)$ were injected with a subconvulsive dose of pilocarpine ( $40.5 \mathrm{mg} / \mathrm{kg}$, s.c.). Rats were video-monitored beginning $14 \mathrm{~d}$ after STEP to document at least two spontaneous seizures before being classified as epileptic. To minimize acute effects of seizures, epileptic rats were further monitored to ensure that no seizures had occurred $24 \mathrm{~h}$ before use. When we intensively monitor epileptic animals prepared identically in our colony, these animals have 1.9 seizures per day on average beginning 2-4 weeks after pilocarpine-induced STEP, and remain epileptic throughout their lives.

Hippocampal slice preparation. Rats were divided into two groups: epileptic $(n=12)$ and control $(n=9)$. Naive rats (i.e., without pilocarpine injections) were also used as controls and results obtained from these animals were not significantly different from controls. Results from sham pilocarpine $(n=3)$ and naive $(n=6)$ animals were therefore pooled together. In all figures, $n$ is the number of rats and slices (one slice recorded per animal) except for Figure 3, where $n$ is the number of slices, and the number of animals in that case was nine in each group. This was because multiple slices were recorded to assure that the reduced area CA1 response was not caused by problems in slice viability. At most, two slices were sampled per animal in this figure, and a similar multiple slice sampling procedure was also conducted in control animals in studies illustrated in this figure. Rats were anesthetized with halothane, decapitated, and the brains removed and blocked in ice-cold artificial CSF (ACSF)sucrose [containing the following (in $\mathrm{mM}$ ): 130 sucrose, $3 \mathrm{KCl}, 1.25$ $\mathrm{NaHPO}_{4}, 1 \mathrm{MgCl}_{2}, 2 \mathrm{CaCl}_{2}, 26 \mathrm{NaHCO}_{3}$, and 10 dextrose], where $\mathrm{NaCl}$ was replaced with sucrose. Hippocampal slices $(400 \mu \mathrm{m})$ were cut at $12^{\circ}$ off horizontal (Rafiq et al., 1993) with a vibrating tissue slicer (VT1000S; Leica, Deerfield, IL). After preparation, slices were transferred into ACSF. For temporoammonic pathway stimulation experiments, a cut between the CA1 and CA3 subfields eliminated possible reentrant activation from $\mathrm{CA} 3$. Slices were transferred to a static interface chamber $\left(34^{\circ} \mathrm{C}\right)$ for $30 \mathrm{~min}$ and then stored at room temperature for up to $6 \mathrm{~h}$.

Optical recording. Slices were stained with $0.125 \mathrm{mg} / \mathrm{ml}$ JPW 3031 (University of Connecticut Health Center) in ACSF for $10 \mathrm{~min}$, and imaged in an oxygenated interface chamber $\left(34 \pm 1^{\circ} \mathrm{C}\right)$ using an $80 \times 80$ CCD camera recording at a $2 \mathrm{kHz}$ frame rate (NeuroCCD; RedShirt Imaging, Decatur, GA). Epi-illumination was provided by a $150 \mathrm{~W}$ Xenon lamp driven by a stable power supply (Opti-quip, Highland Mills, $\mathrm{NY})$. The CCD chip well size $\left(215,000 \mathrm{e}^{-}\right)$requires use of low light intensities, which minimized photodynamic damage. A $4 \times$ objective lens (0.28 numerical aperture; Olympus, Tokyo, Japan) imaged a $2.5 \times$ $2.5 \mathrm{~mm}$ region in hippocampal area CA1 $(32 \times 32 \mu \mathrm{m}$ region imaged per pixel). Similar to previous studies (Ang et al., 2005), we demonstrate a close correlation of the voltage-sensitive dye response with the simulta- neous recordings from the apical dendrite in stratum radiatum, in response to Schaffer collateral stimulation (supplemental Fig. $1 B$, available at www.jneurosci.org as supplemental material). In controls, for eight patch recording/voltage-sensitive dye experiments, the slope of the linear correlation was $0.11 \pm 0.0055 \% \Delta \mathrm{F} / \mathrm{F} / 10 \mathrm{mV}$ (supplemental Fig. $1 B$, inset, available at www.jneurosci.org as supplemental material). In epileptic animals, neuronal cell loss, pruning of dendritic trees, and gliosis result in reduction of the fractional change in fluorescence $(\Delta F / F)$ for the unit change in membrane potential. In epileptic animals, for five patch recording/voltage sensitive dye experiments, the slope of the change in fluorescence/membrane potential correlation was $0.066 \pm 0.0016 \% \Delta \mathrm{F} /$ F/10 mV (supplemental Fig. $1 D$, available at www.jneurosci.org as supplemental material).

Electrophysiological methods. A bipolar electrode (World Precision Instruments, Sarasota, FL) was positioned within $100 \mu \mathrm{m}$ of the hippocampal fissure to stimulate temporoammonic axons (see Fig. $1 \mathrm{~A}$, illustration) (Steward and Scoville, 1976). Stimuli, consisting of $200 \mu$ s, $40-100$ $\mu \mathrm{A}$ pulses, were delivered through stimulus isolation units (World Precision Instruments). Schaffer collateral and perforant path stimulation were administered with the electrode placed near the border of CA1 and in the perforant path axon bundle proximal to the angular bundle, respectively. Each stimulus trial was $\geq 20 \mathrm{~s}$ apart. Whole-cell dendritic patch recordings were performed using blind patch techniques (Blanton et al., 1989), electrodes (6-8 M $\Omega$ ) were filled with potassium gluconatebased intracellular solution [containing the following (in $\mathrm{mM}$ ): 145 K-gluconate, $2 \mathrm{MgCl}_{2}$, $2 \mathrm{ATP} \cdot \mathrm{Mg}, 0.5 \mathrm{GTP} \cdot$ tris, $0.1 \mathrm{BAPTA}, 2.5 \mathrm{KCl}, 2.5$ $\mathrm{NaCl}$, and $10 \mathrm{HEPES}]$. An Axoclamp 2A was used to perform currentclamp recordings.

Data analysis. All analysis was performed in IGOR (Wavemetrics, Lake Oswego, OR) on 12 trial averages. Data were displayed as the change in fluorescence divided by the resting fluorescence $(\Delta \mathrm{F} / \mathrm{F})$. To be consistent with electrophysiological conventions, depolarizing $\Delta \mathrm{F} / \mathrm{F}$ signals were displayed as positive signals (warmer colors) and hyperpolarizations represented as negative signals (colder colors). Significance was assessed at $p \leq 0.05$ level. ANOVA was performed where appropriate. All results are reported as mean \pm SEM.

\section{Results}

The role of the dentate gyrus in TLE has been of interest because this structure functions as a checkpoint regulating cortical information flow into the hippocampus (Heinemann et al., 1992; Lothman et al., 1992; Behr et al., 1998; Nadler, 2003). To assess the gating function of the dentate gyrus in response to entorhinal cortical input, a perforant path burst stimulus (four pulses, 100 $\mathrm{Hz}$ ) was applied. In controls, this generated a large response over the whole molecular layer. Despite this powerful activation of the dentate gyrus, propagation of excitatory activity to CA3 was effectively constrained (Fig. $1 A$ ). This suppression was not a result of damage to CA3, because antidromic stimulation of the Schaffer collaterals evoked a strong voltage-sensitive dye recorded CA3 EPSP, demonstrating the presence of viable CA3 neurons (Fig. $1 A$, insets). Because throughput into CA3 could result in localized excitation that would be lost to averaging responses over large areas (compare Fig. 1C), we summed the number of pixels in the dentate gyrus and area CA3a that exhibited significant depolarization after perforant path stimulation $(>0.04 \% \Delta \mathrm{F} / \mathrm{F}$, corresponding to responses $\geq 3$ SDs over noise levels). The activated pixel number was normalized against the total pixel number in each region of interest, generating a percent area activated measure, and plotted against time (Fig. 1 E). This "areal analysis" revealed a measurable signal in CA3. Epileptic animals did not show differences in the amplitude or spatial extent of dentate gyrus or CA3 activation compared with controls (Fig. 1B-D) $(p=0.94)$. These data demonstrate that, in this animal model of TLE, dentate gyrus function is preserved, and propagation of 
entorhinal input to area CA3 is appropriately limited after perforant path activation using this stimulation protocol.

Downstream transmission from area CA3 to area CA1 was reduced in epileptic animals. Axons of CA3 pyramidal cells targeting the proximal CA1 apical dendrites (the Schaffer collaterals) form a major excitatory input to these cells. To assess changes in this pathway, we activated the Schaffer collaterals with single stimuli and measured the extent of spatial activation. In controls, pixels that showed $>0.05 \%$ $\Delta \mathrm{F} / \mathrm{F}$ were counted, corresponding to $>5$ $\mathrm{mV}$ depolarization recorded in simultaneous patch recordings $(n=5)$. In epileptic animals, because of the smaller $\Delta \mathrm{F} / \mathrm{F}$ change per millivolt (supplemental Fig. 1, available at www.jneurosci.org as supplemental material), pixels with a $5 \mathrm{mV}$ depolarization showed $0.035 \% \Delta \mathrm{F} / \mathrm{F}$ (corresponding to a response $\geq 3$ SDs over noise levels; $n=5$ ). In controls, Schaffer inputs activated at peak a majority of the pixels present in CA1 (Fig. $2 A, D$ ). In contrast, in epileptic animals, Schaffer collateral stimulation produced a reduced excitatory response in both amplitude and area (Fig. $2 B-D)$. Epileptic animals showed significantly smaller maximal CA1 activation area compared with controls, (Fig. 2E) (control, $87.5 \pm 2.9 \%$; epileptic, $35.56 \pm$ $7.69 \%$; ANOVA, ${ }^{\star} p \leq 0.05 ; n=12$ ). Thus, the impaired Schaffer collateral synaptic response would further limit propagation of seizure activity from the entorhinal cortex via the dentate gyrus into the hippocampus.

We next examined an alternative cortical afferent: the temporoammonic pathway (Fig. 3, circuit diagram). Because layer III neurons of the entorhinal cortex generate high-frequency bursts and bursting behavior is likely in epilepsy (Chrobak and Buzsaki, 1998), a burst stimulation of the temporoammonic pathway was used that evoked a summating EPSP. In controls, this summed EPSP was highly restricted to a strip 100-150 $\mu \mathrm{m}$ wide in the distal apical dendritic tuft of CA1 neurons. In contrast, a membrane hyperpolarization of $-0.02 \pm 0.014 \% \Delta \mathrm{F} / \mathrm{F}(n=6)$ was recorded more proximally in stratum radiatum (Fig. 3A). Consistent with our previous studies (Ang et al., 2005), these results demonstrate that feedforward inhibition spatially compartmentalizes temporoammonic pathway activity to the distal dendrites of CA1 neurons.

This pattern of distal excitation concurrent with proximal inhibition after temporoammonic activation was lost in slices from rats with TLE. Stimulation of the temporoammonic pathway evoked EPSPs that propagated to stratum radiatum $(0.067 \pm$ $0.013 \% \Delta \mathrm{F} / \mathrm{F} ; n=6$ ), demonstrating a loss of temporoammonic input spatial restriction to CA1 stratum lacunosum moleculare (Fig. 3B, supplemental Fig. 2, available at www.jneurosci.org as supplemental material). Compared with controls, temporoammonic pathway responses in epileptic animals were increased, reflected as a prolonged, spatially extensive activation (Fig. 3C). At all time points, epileptic animals showed a greater area of activation than controls (Fig. $3 D$ ) (ANOVA, ${ }^{\star} p \leq 0.05 ; n=12$ ). To quantify the length of time in which pixels remained depolarized by temporoammonic inputs, we integrated the area under the trace that represents the spatial extent of activation (Fig. 3C). Compared with control, epileptic animals demonstrated a much greater activated area time integral (Fig. 3E) (control, $1.29 \pm$ $0.3 \% \times$ ms; epileptic, $13.46 \pm 2.8 \% \times$ ms; ANOVA, ${ }^{\star} p \leq 0.05$; 
A

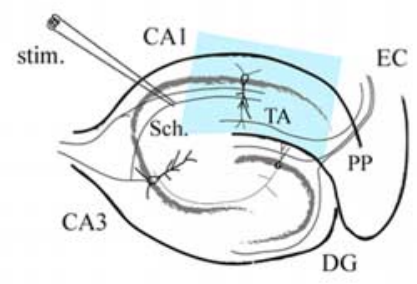

B

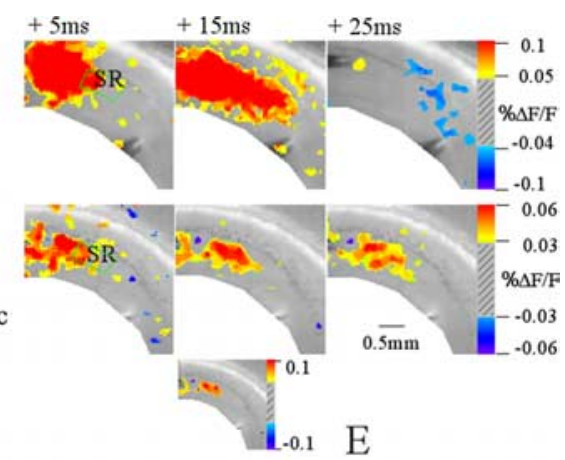

C

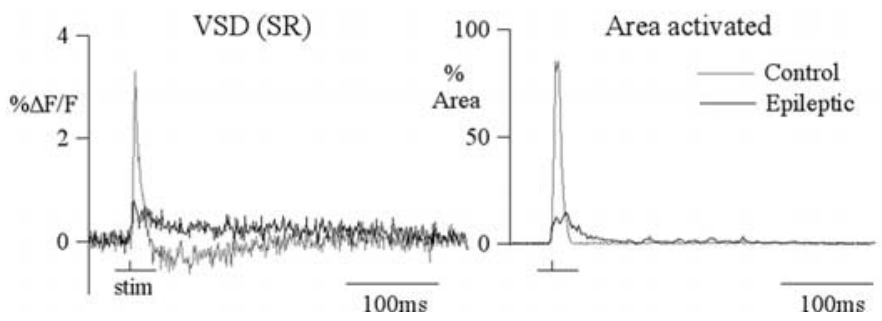

Figure 2. Impairment in Schaffer collateral-evoked responses in epilepsy. $\boldsymbol{A}$, The schematic of the hippocampus illustrates the major afferent pathways to the hippocampus and the position of the stimulation electrode that is used to activate the Schaffer collaterals (stim.). The blue area indicates the typical area imaged with our camera for CA1 studies. $B$, Snapshots of VSD recordings from control and epileptic slices at 5, 15, and $25 \mathrm{~ms}$ after the response to a stimulus ( $200 \mu$ s pulses at 50-100 $\mu \mathrm{A}$ ) applied at stratum radiatum to activate the $S$ chaffer collaterals $(S c h$.). To capture the responses that were smaller in slices from epileptic animals (supplemental Fig. 1, available at www.jneurosci.org as supplemental material), we mapped the snapshots to a smaller color scale; for comparison, the inset $(\boldsymbol{B})$ shows peak response mapped to control color bar. Note the powerful excitatory activation of the Schaffer collaterals in control and the reduced Schaffer response in epileptic tissue. C, Traces showing VSD signals averaged from regions of interest in CA1 stratum radiatum (SR; green box) from control and epileptic are superimposed, contrasting a strong EPSP-IPSP sequence in control and the weak EPSP in epileptic. Focusing on the excitation generated in both conditions, the percentage of the total area in CA1 activated by Schaffer collateral stimulation is plotted against time. For the purposes of analysis, this area was delineated as a wedge shape between the alveus and hippocampal fissure, with sides drawn perpendicular to both curved boundaries to generate a consistent region of interest in all slices. Because simultaneous current clamp records show reduced $\Delta F / F$ per membrane voltage change in recordings from epileptic slices compared with controls (supplemental Fig. 1 , available at www.jneurosci.org as supplemental material), to reduce the chance of underestimating responses from slices derived from epileptic animals, pixels showing depolarizations of greater than a calculated $5 \mathrm{mV}$ change $(0.05 \% \Delta \mathrm{F} / \mathrm{F}$ for control and $0.035 \% \Delta \mathrm{F} / \mathrm{F}$ for epileptic) were counted. $\boldsymbol{D}$, This also demonstrated a large amplitude, brief response in controls compared with a prolonged but more limited amplitude response from epileptic animals. $\boldsymbol{E}$, In group data this is illustrated: more then $70 \%$ of pixels in the region of interest are activated in control slices after Schaffer stimulation, whereas a significantly more limited and variable activation is seen in slices from epileptic animals (ANOVA, ${ }^{*} p \leq 0.05$ ). PP, Perforant path; DG, dentate gyrus; EC, entorhinal cortex; TA, temporoammonic pathway.

$n=12$ ). Despite the smaller change in fluorescence of epileptic tissues per unit voltage, when the threshold was raised to be identical to controls $(0.05 \% \Delta \mathrm{F} / \mathrm{F})$ (Fig. $3 C$, dotted line), the finding of increased temporoammonic evoked activity remained significantly greater than controls $\left(10.6 \pm 2.6 \% \times \mathrm{ms}\right.$; ANOVA, ${ }^{\star} p \leq$ $0.05 ; n=12$ ).

To further determine the impact of temporoammonic dysregulation in animals with epilepsy, we conducted patch-clamp recordings from the apical dendrites of CA1 pyramidal neurons and assessed responses to temporoammonic activation. In controls, whole-cell recordings from stratum radiatum predominantly exhibited membrane hyperpolarizations after temporoammonic activation (Fig. $4 A)(-2.9 \pm 0.59 \mathrm{mV} ; n=5)$. In contrast, dendritic recordings from epileptic tissue displayed large depolarizations (Fig. $4 B)(10.3 \pm 1.2 \mathrm{mV} ; n=5)$ with one cell spiking. Because the temporoammonic pathway consists of axons from layer III entorhinal cortical neurons that can fire prolonged high-frequency bursts in vivo (Chrobak and Buzsaki, 1998) and entorhinal cortical bursting is often found TLE, our brief burst stimulus at $100 \mathrm{~Hz}$ may underestimate the intensity of entorhinal cortical input and its dysregulated response in epileptic animals.

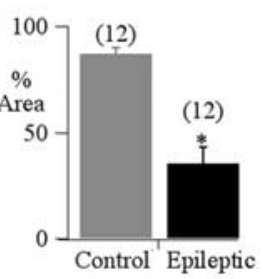

Control Epileptic
The summary histogram plotting the relative spatial activation of the perforant path, Schaffer collaterals, and temporoammonic pathway in slices prepared from epileptic animals relative to controls (Fig. $4 B$, inset) reiterate that whereas other hippocampal pathways remained unchanged or exhibited reduced activation, the temporoammonic pathway was transformed selectively from a constrained input, producing net inhibition in CA1 pyramidal cells, to a powerful excitatory projection in this animal model of epilepsy.

\section{Discussion}

The most parsimonious conclusions from the data described above are clear. The specific transformation of the temporoammonic input from a primarily inhibitory to powerfully excitatory CA1 afferent suggests a prominent role for the entorhinal-CA1 axis during hippocampal activation in epileptic animals. In contrast, the maintained efficacy of dentate gatekeeper function and reduced coupling of activity from CA3 to CA1 via the Schaffer collaterals makes it less likely that, in animal models of TLE, the classic trisynaptic circuitry is aberrantly activated by the entorhinal cortex to generate a reverberating limbic loop discharge underlying seizures. However, these findings are derived from in vitro studies, using necessarily artificial stimulation protocols. Additional corroboration of the maintained function of the dentate gatekeeper function in TLE will require additional studies using a more thorough analysis of stimulation parameters and follow-up studies in vivo in animal models of TLE.

It has been shown previously that activation of the temporoammonic pathway can generate a burst of action potentials in pilocarpine-treated animals, demonstrating facilitation of the direct excitatory pathway from the entorhinal cortex in epilepsy (Cossart et al., 2001; Wozny et al., 2005). However, to our knowledge, no other study has quantified directly the relative degree of circuit disruption in multiple hippocampal pathways from the same epileptic animals, particularly at the spatial and temporal resolution made possible by high-speed voltage-sensitive dye imaging. Based on the selective enhancement in the temporoammonic inputs to CA1, and the fact that, in human TLE and in pharmacological models of epilepsy in vitro, epileptiform discharges are known to be generated in the entorhinal cortex (Spencer and Spencer 1994; Barbarosie et al., 2000), our data then suggests that, in TLE, bursting in the entorhinal cortex may selectively and powerfully activate area CA1.

Epileptic animals from our experimental population do show many of the hallmarks of human TLE, including cell loss in the hilus, and some disruption of the hippocampal pyramidal cell layers (Mathern et al., 1996) (supplemental Fig. 3, available at www.jneurosci.org as supplemental material). Some of these hippocampal changes likely underlie the reduction in Schaffer 
B

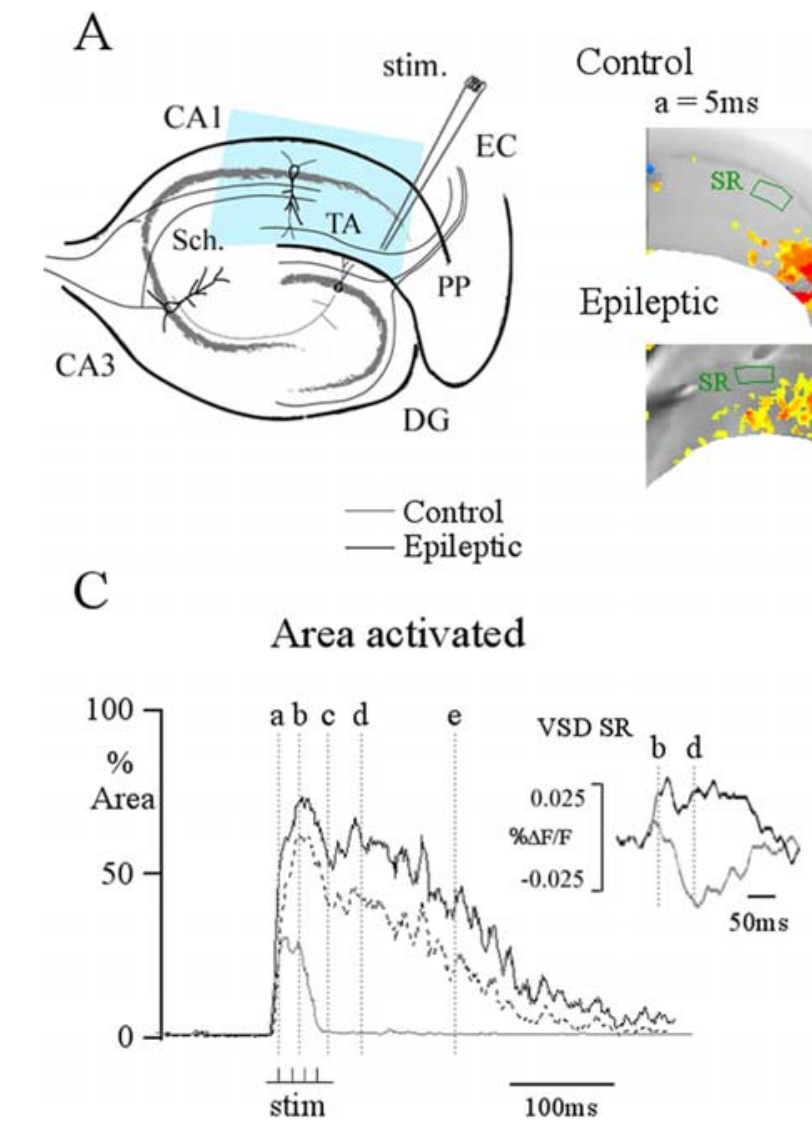

Area activated

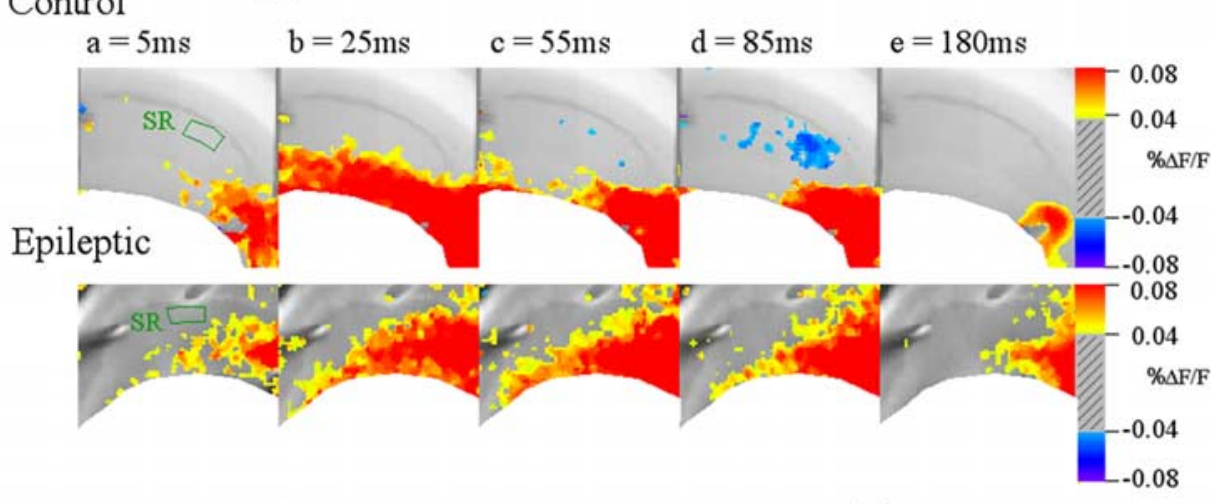

$\mathrm{D}$

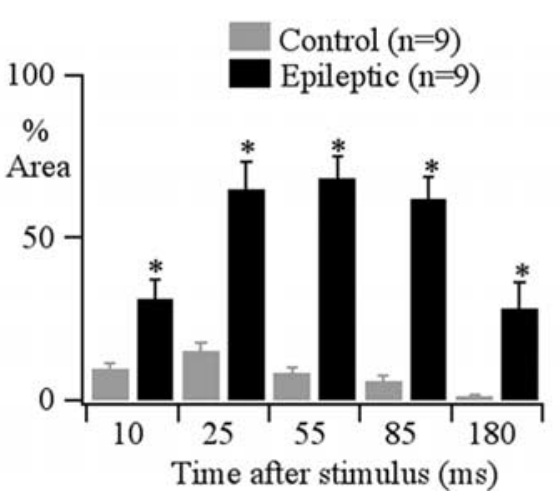

$\mathrm{E}$
Integrated Area
(\% Area Activated $\times \mathrm{ms})$ 20

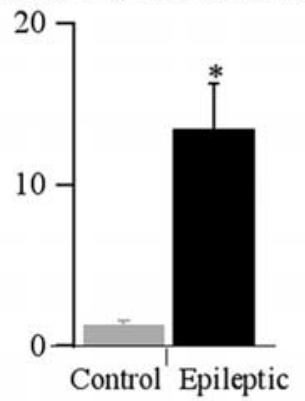

Figure 3. Excitation evoked by activation of the temporoammonic pathway is increased by an order of magnitude in area $(A 1 . A$, The schematic of the hippocampus illustrates the major afferent pathways to the hippocampus and the position of the stimulation electrode that is used to activate the temporoammonic pathway (stim.). The blue area indicates typical area imaged with our camera. $\boldsymbol{B}$, VSD recording snapshots of control and epileptic responses at 5, 25,55, 85, and $180 \mathrm{~ms}$ after response to a burst stimulation (four stimuli at $100 \mathrm{HZ}, 200 \mu \mathrm{s}$ pulses at $50-100 \mu \mathrm{A}$ ) applied to the temporoammonic pathway at the angular bundle. This stimulus produces spatially restricted temporoammonic activity in control. In contrast, in epileptic tissue, excitation is propagated throughout the stratum radiatum and pyramidale. This is demonstrated in $C$, by comparing the percentage of the total CA1 area activated by temporoammonic stimulation in control (gray) and epileptic (black) plotted against time. Pixels showing depolarizations of $>0.05 \% \Delta \mathrm{F} / \mathrm{F}$ for control and $0.035 \% \Delta \mathrm{F} / \mathrm{F}$ for epileptic are counted, normalized to the total CA1 area imaged (for comparison dotted line shows epileptic response when threshold is set at $0.05 \% \Delta \mathrm{F} / \mathrm{F})$. This reveals a greater area and prolonged period of activation in epileptic tissue compared with controls, inset traces depicting percent change in fluorescence shows that this is caused in part by loss of inhibition, with an IPSP present in the stratum radiatum (SR) in control animals, which is transformed into an EPSP in epileptic animals. D, Summary data illustrates both the differences in peak amplitude and time course of area activated for control (gray) compared against epileptic (black) for time points of $10,25,55,85$, and $180 \mathrm{~ms}$. An asterisk indicates that epileptic animals demonstrate a significant increase in the maximum area activated by temporoammonic stimulation over control for the selected time points. $\boldsymbol{E}$, These results can be summarized as a simple comparison by integrating the area under the percent pixel activated traces, capturing both the number and duration of pixels activated, which illustrates a $>10$-fold increase in activation in slices from epileptic animals compared with controls (ANOVA, ${ }^{*} p \leq 0.05 ; n=12$ ). PP, Perforant path; DG, dentate gyrus; TA, temporoammonic pathway; EC, entorhinal cortex.

collateral-coupling between CA3 and CA1 as well as the reduction in Schaffer-activated inhibition in CA1 evident in our results (Fig. 2). Although it should be noted that the role of a hyperexcitable temporoammonic response would likely be blunted in cases where there is severe cell loss in layer III of the entorhinal cortex or extensive loss of CA1 pyramidal cells (as is seen in subsets of patients undergoing temporal lobectomy for intractable TLE), the pathology found in our pilocarpine treated rats is analogous to many patients with TLE (Dawodu and Thom, 2005). Additional studies examining potential correlations in seizure frequency, pathology, and function of entorhinal and hippocampal circuitry will be needed to better understand the many possible interactions of pathology and activity present in the full range of TLE severity found in both rodent models and humans.

What mechanisms might contribute to the selective dysregulation of the temporoammonic pathway in epileptic animals? In controls, the temporoammonic pathway is strongly regulated by feedforward inhibition. This inhibition, evoked synaptically by temporoammonic afferent stimulation, plays an important role in limiting cell firing. Blockade of inhibition unmasks a strong excitation in CA1 pyramidal cells after activation of the temporoammonic pathway (Ang et al., 2005). In animals with chronic epilepsy, a partial loss of feedforward inhibition could produce a loss of spatial segregation of temporoammonic inputs, resulting in strong depolarization of the CA1 dendrites and soma. Selective lesion of layer III neurons in the entorhinal cortex using focal injections of aminooxyacetic acid has been shown to disrupt inhibitory processes in the hippocampus area CA1, leading to a hypothesis postulating that partial loss of layer III entorhinal cortical neurons may contribute to reductions in feedforward inhibition in area CA1, amplifying the temporoammonic pathway (Denslow et al., 2001). In patients with TLE and in pilocarpine animal models of epilepsy, cell loss in layer III of the entorhinal cortex has been shown (Du et al., 1993, 1995) (supplemental Fig. 3, available at www.jneurosci.org as supplemental material). Therefore, loss of entorhinal cortical layer III neurons in pilocarpine-treated rats could result in partial deafferentation of inhibitory neurons in the temporoammonic pathway, produc- 
A

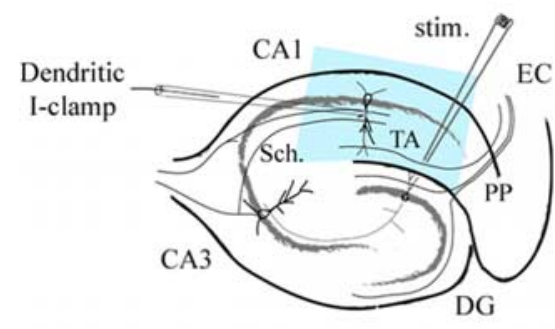

$\mathrm{D}$

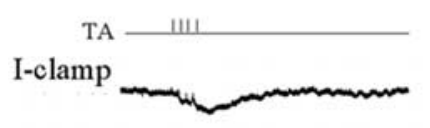

SRD

VSD

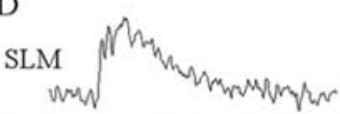

E

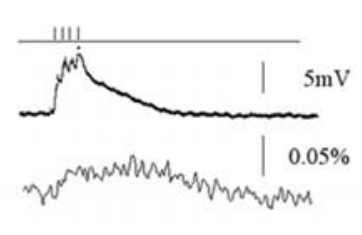

B

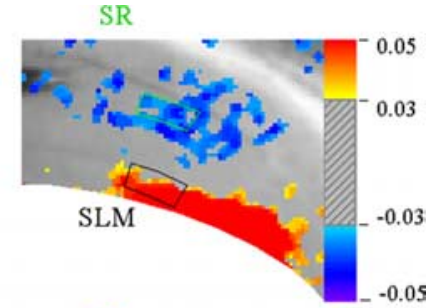

$\mathrm{C}$

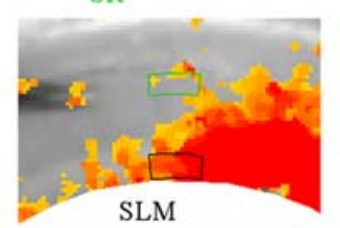

F $\%$ Pixels Activated Relative to Control

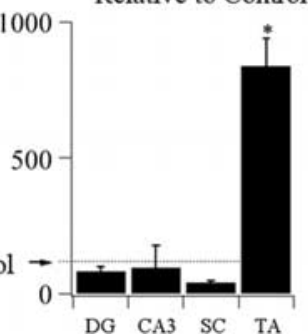

Figure 4. Transformation of the temporoammonic pathway from an inhibitory, spatially restricted pathway to a powerful excitatory projection in epileptic animals. $\boldsymbol{A}$, The schematic of the hippocampus illustrates the major afferent pathways to the hippocampus and the position of the stimulation electrode that is used to activate the temporoammonic pathway (stim.) as well as the position of the patch electrode used for the dendritic whole-cell records. The blue area indicates the typical area imaged with our camera. $\boldsymbol{B}$, The control is a VSD recording snapshot of EPSP activation at $30 \mathrm{~ms}$ evoked by burst stimulation (four stimuli at $100 \mathrm{HZ}, 200 \mu$ s pulses at $50-100 \mu \mathrm{A}$ ) applied to the temporoammonic pathway in a slice prepared from a control animal, showing distal depolarization (red) and concurrent more proximal inhibition (blue). Sch., Schaffer collaterals. I-clamp dendritic shows the whole-cell recording from the apical dendrite of a CA1 pyramidal cell in stratum radiatum (SR), which exhibited a small IPSP. VSD traces, SR and SLM are the local VSD signals quantified from regions of interest in stratum radiatum (green box) and stratum lacunosum moleculare (black box) respectively. C, Epileptic. A VSD recording snapshot of the EPSP at $30 \mathrm{~ms}$ evoked by temporoammonic stimulation in a slice prepared from an epileptic animal is shown. Note that the temporoammonic-evoked EPSP is not spatially restricted to the distal dendrites in stratum lacunosum moleculare but propagates to stratum radiatum, depolarizing the proximal dendrites. $\boldsymbol{D}, \boldsymbol{E}$, A dendritic whole-cell recorded response (control, $\boldsymbol{D}$; epileptic, $\boldsymbol{E}$; top trace), shows a concurrent $9.3 \mathrm{mV}$ EPSP during the temporoammonic VSD EPSP in SR and SLM (middle and bottom traces). $\boldsymbol{F}$, Summary data for all hippocampal pathways tested comparing maximal area of activation in slices from epileptic animals relative to control in the dentate gyrus (DG) and CA3 in response to perforant path stimulation, in CA1 in response to Schaffer collaterals (SC) and temporoammonic pathway stimulation demonstrating the dramatic increase in excitability is limited to TA activation of area CA1 ( $n=8$ for DG and $\mathrm{CA} 3 ; n=12$ for SC and TA; ANOVA, $\left.{ }^{*} p \leq 0.05\right)$. TA, Temporoammonic pathway; EC, entorhinal cortex.

ing disinhibition of CA1 pyramidal neurons (Wozny et al., 2005). Feedforward inhibition may also be compromised by loss of interneurons (Houser and Esclapez, 1996; Dinocourt et al., 2005). It is also possible that intrinsic, regenerative boosting effects on temporoammonic EPSPs mediated by upregulation of T-type $\mathrm{Ca}^{2+}$ conductance and downregulation of A-type potassium and hyperpolarization-activated $\mathrm{H}$-type cationic conductances in CA1 pyramidal cell dendrites may contribute to enhanced efficacy in this pathway (Su et al., 2002; Shah et al., 2004; Bernard et al., 2004).

Our estimates of a selective 10-fold increase in the efficacy of the temporoammonic pathway in epileptic animals may actually significantly underestimate the degree of disruption of this circuit. In addition to being regulated by powerful feedforward inhibition, this pathway is also extensively and selectively gated by specific sets of feedback interneurons, the oriens/alveus interneurons, which are activated by CA1 pyramidal neurons, and project powerfully to the afferent innervation zone of the temporoam- monic input, stratum lacunosum/moleculare (termed OA-SLM interneurons). Once CA1 neurons activate, these OASLM interneurons will normally shut off the temporoammonic input in a feedback manner, preventing reentrant activation and further regulating this pathway (Lacaille et al., 1987; Yanovsky et al., 1997; Ang et al., 2005). However, in epileptic animals, these interneurons are selectively lost (Houser and Esclapez, 1996; Morin et al., 1998; Dinocourt et al., 2005), which would remove a further check on this pathway, allowing reentrant activity to proceed unchecked. This could potentially provide an additional mechanism whereby the direct entorhinal cortical/ CA1 pathway may facilitate seizure discharge initiation in limbic circuits.

This massive and specific disruption of the temporoammonic pathway in TLE, combined with the fact that the area CA1 activity evoked by this pathway will directly reactivate entorhinal cortex in a tight loop excitatory connection (Pare et al., 1992), may serve to critically position temporoammonic input to participate in the generation of hippocampal seizure activity. These results further identify the temporoammonic pathway as a potentially important site for therapeutic targeting in TLE.

\section{References}

Ang CW, Carlson GC, Coulter DA (2005) Hippocampal CAl circuitry dynamically gates direct cortical inputs preferentially at theta frequencies. J Neurosci 25:9567-9580.

Barbarosie M, Louvel J, Kurcewicz I, Avoli M (2000) CA3-released entorhinal seizures disclose dentate gyrus epileptogenicity and unmask a temporoammonic pathway. J Neurophysiol 83:1115-1123.

Behr J, Lyson KJ, Mody I (1998) Enhanced propagation of epileptiform activity through the kindled dentate gyrus. J Neurophysiol 79:1726-1732.

Bernard C, Anderson A, Becker A, Poolos NP, Beck H, Johnston D (2004) Acquired dendritic channelopathy in temporal lobe epilepsy. Science 305:532-535.

Bertram EH (1997) Functional anatomy of spontaneous seizures in a rat model of epilepsy. Epilepsia 38:95-105.

Blanton MG, LoTurco JJ, Kriegstein AR (1989) Whole cell recording from neurons in slices of reptilian and mammalian cerebral cortex. J Neurosci Methods 30:203-210.

Buckmaster PS, Dudek FE (1997) Neuron loss, granule cell axon reorganization and functional changes in the dentate gyrus of epileptic kainate treated rats. J Comp Neurol 385:385-404.

Chrobak JJ, Buzsaki G (1998) Gamma oscillations in the entorhinal cortex of the freely behaving rat. J Neurosci 18:388-398.

Contreras D, Llinás R (2001) Voltage-sensitive dye imaging of neocortical spatiotemporal dynamics to afferent activation frequency. J Neurosci 21:9403-9413.

Cossart R, Dinocourt C, Hirsch JC, Merchan-Perez A, De Felipe J, Ben-Ari Y, Esclapez M, Bernard C (2001) Dendritic but not somatic GABAergic inhibition is decreased in experimental epilepsy. Nat Neurosci 4:52-62.

Davila HV, Salzberg BM, Cohen LB, Waggoner AS (1973) A large change in 
axon fluorescence that provides a promising method for measuring membrane potential. Nat New Biol 241:159-160.

Dawodu S, Thom M (2005) Quantitative neuropathology of the entorhinal cortex region in patients with hippocampal sclerosis and temporal lobe epilepsy. Epilepsia 46:23-30.

Denslow MJ, Eid T, Du F, Schwarcz R, Lothman EW, Steward O (2001) Disruption of inhibition in area CA1 of the hippocampus in a rat model of temporal lobe epilepsy. J Neurophysiol 86:2231-2245.

Dinocourt C, Petanjek Z, Freund TF, Ben-Ari Y, Esclapez M (2005) Loss of interneurons innervating pyramidal cell dendrites and axon initial segments in the CA1 region of the hippocampus following pilocarpineinduced seizures. J Comp Neurol 459:407-425.

Du F, Whetsell WO, Abou-Khalil B, Blumenkopf B, Lothman EW, Schwarcz R (1993) Preferential neuronal loss in layer III of the entorhinal cortex in patients with temporal lobe epilepsy. Epilepsy Res 16:223-233.

Du F, Eid T, Lothman EW, Köhler C, Schwarcz R (1995) Preferential neuronal loss in layer III of the medial entorhinal cortex in rat models with temporal lobe epilepsy. J Neurosci 15:6301-6313.

Engel JJ (1995) Introduction to temporal lobe epilepsy. Epilepsy Res 26:141-150.

Falconer MA, Serafetinides EA, Corsellis JAN (1964) Etiology and pathogenesis of temporal lobe epilepsy. Arch Neurol 10:233-248.

French JA, Williamson PD, Thadani VM, Darcey TM, Mattson RH, Spencer SS, Spencer DD (1993) Characteristics of medial temporal lobe epilepsy. I. Results of history and physiology examination. Ann Neurol 34:774-780.

Gibbs JW, Shumate MD, Coulter DA (1997) Differential epilepsy associated alterations in postsynaptic $\mathrm{GABA}(\mathrm{A})$ receptor function in dentate granule and CA1 neurons. J Neurophysiol 77:1924-1938.

Heinemann U, Beck H, Dreier JP, Ficker E, Stabel J, Zhang CL (1992) The dentate gyrus as a regulated gate for the propagation of epileptiform activity. Epilepsy Res Suppl 7:273-280.

Houser CR, Esclapez M (1996) Vulnerability and plasticity of the GABA system in the pilocarpine model of spontaneous recurrent seizures. Epilepsy Res 26:207-218.

Houser CR, Miyashiro JE, Swartz BE, Walsh GO, Rich JR, Delgado-Escueta AV (1990) Altered patterns of dynorphin immunoreactivity suggest mossy fiber reorganization in human hippocampal epilepsy. J Neurosci 10:267-282.

Lacaille JC, Mueller AL, Kunkel DD, Schwartzkroin PA (1987) Local circuit interactions between oriens/alveus interneurons and CA1 pyramidal cells in hippocampal slices: electrophysiology and morphology. J Neurosci 7:1979-1993.

Lothman EW, Stringer JL, Bertram EH (1992) The dentate gyrus as a control point for seizures in the hippocampus and beyond. Epilepsy Res Suppl 7:301-313.

Mathern GW, Babb TL, Leite JP, Pretorius JK, Yeoman KM, Kuhlman PA (1996) The pathogenic and progressive features of chronic human hippocampal epilepsy. Epilepsy Res 26:151-161.

Mello LE, Cavalheiro EA, Tan AM, Kupfer WR, Pretorius JK, Babb TL, Finch DM (1993) Circuit mechanisms of seizures in the pilocarpine model of chronic epilepsy: cell loss and mossy fiber sprouting. Epilepsia 34:985-995.
Morin F, Beaulieu C, Lacaille JC (1998) Selective loss of GABA neurons in area $\mathrm{CA} 1$ of the rat hippocampus after intraventricular kainate. Epilepsy Res 32:363-369.

Nadler JV (2003) The recurrent mossy fiber pathway of the epileptic brain. Neurochem Res 28:1649-1658.

Ojemann GA (1987) Surgical therapy for medically intractable epilepsy. J Neurosurg 66:489-499.

Pare D, deCurtis M, Llinas R (1992) Role of the hippocampal-entorhinal loop in temporal lobe epilepsy: extra- and intracellular study in the isolated guinea pig brain in vitro. J Neurosci 12:1867-1881.

Rafiq A, DeLorenzo RJ, Coulter DA (1993) Generation and propagation of epileptiform discharges in a combined entorhinal cortex/hippocampal slice. J Neurophysiol 70:1962-1974.

Salzberg BM, Davila HV, Cohen LB (1973) Optical recording of impulses in individual neurons of an invertebrate central nervous system. Nature 246:508-509.

Schwartzkroin PA, Knowles WD (1984) Intracellular study of human epileptic cortex: in vitro maintenance of epileptiform activity? Science 223:709-712.

Shah MM, Anderson AE, Leung V, Lin X, Johnston D (2004) Seizureinduced plasticity of h channels in enthorhinal cortical layer III pyramidal neurons. Neuron 44:495-508.

Sloviter RS, Zappone CA, Harvey BD, Frotscher M (2006) Kainic acidinduced recurrent mossy fiber innervation of dentate gyrus inhibitory interneurons: possible anatomical substrate of granule cell hyperinhibition in chronically epileptic rats. J Comp Neurol 494:944-960.

Spencer SS, Spencer DD (1994) Entorhinal-hippocampal interactions in medial temporal lobe epilepsy. Epilepsia 35:721-727.

Steward O, Scoville SA (1976) Cells of origin of entorhinal cortical afferents to the hippocampus and fascia dentate of the rat. J Comp Neurol 169:347-370.

Su H, Sochivko D, Becker A, Chen J, Jiang Y, Yaari Y, Beck H (2002) Upregulation of a T-type $\mathrm{Ca}^{2+}$ channel causes a long-lasting modification of neuronal firing mode after status epilepticus. J Neurosci 22:3645-3655.

Sutula T, XiaoXian H, Cavazos J, Parada I, Ramirez L (1988) Synaptic reorganization in the hippocampus induced by abnormal functional activity. Science 239:1147-1150.

Wilson CL, Khan SU, Engel JJ, Isokawa M, Babb TL, Behnke EJ (1998) Paired pulse suppression and facilitation in human epileptogenic hippocampal formation. Epilepsy Res 31:211-230.

Wozny C, Gabriel S, Jandova K, Schulze K, Heinemann U, Behr J (2005) Entorhinal cortex entrains epileptiform activity in CA1 in pilocarpinetreated rats. Neurobiol Dis 19:451-460.

Wu K, Leong LS (2001) Enhanced but fragile inhibition in the dentate gyrus in vivo in the kainic acid model of temporal lobe epilepsy: a study using current source density analysis. Neuroscience 104:1067-1077.

Yanovsky Y, Sergeeva OA, Freund TF, Haas HL (1997) Activation of interneurons at the stratum oriens/alveus border suppresses excitatory transmission to apical dendrites in the CA1 area of the mouse hippocampus. Neuroscience 77:87-96. 